\title{
Telemetry Tracking During Directional Drilling
}

\author{
Tanyana IVANOVA ${ }^{1 *}$ and Aleksandr KORSHUNOV ${ }^{2}$
}

\begin{abstract}
Authors' affiliations and addresses:
${ }^{1}$ Federal State Budgetary Institution of Science "Udmurt Federal Research Center of the Ural Branch of the Russian Academy of Sciences ", Institute of Mechanics, 426000, T. Baramzinoy str., 34, Izhevsk, Russia

Tchaikovsky Branch "Perm National Research Polytechnic Institute", 617764, Lenin st., 73,

Tchaikovsky, Russia

e-mail: tatnic2013@yandex.ru
\end{abstract}

${ }^{2}$ Federal State Budgetary Institution of Science "Udmurt Federal Research Center of the Ural Branch of the Russian Academy of Sciences ", Institute of Mechanics, 426000, T. Baramzinoy str., 34, Izhevsk, Russia

e-mail: maguser_kai@mail.ru

\section{*Correspondence:}

Tanyana Ivanova, Federal State Budgetary Institution of Science "Udmurt Federal Research Center of the Ural Branch of the Russian Academy of Sciences", Institute of Mechanics, 426000, T. Baramzinoy str., 34, Izhevsk, Russia e-mail: tatnic2013@yandex.ru

\section{How to cite this article:}

Ivanova, T. and Korshunov, A. (2021). Telemetry Tracking During Directional Drilling. Acta Montanistica Slovaca, Volume 26 (1), 127-138

DOI:

https://doi.org/10.46544/AMS.v26i1.11

\begin{abstract}
The article discusses the main features of the organization of telemetry in directional drilling. The constant increase in the complexity of the conditions for the development and operation of fields, oil and gas production, an increase in the intensity of development of already explored fields due to horizontal and cluster drilling required a significant increase in the requirements for the accuracy of diagnostics and active control of the spatial position of the field. In general, the accuracy of measurements and the efficiency of their processing largely determine the cost of well construction. Directional drilling is one of the well construction methods. The most effective directional drilling application is the development of fields located in water areas, in swampy or rugged terrain, where the construction of drilling rigs may violate the requirements for environmental protection and environmental safety. Directional drilling is also widely used in the creation of relief wells for killing blowouts, for forming multilateral wells or deviating the lower part of the well along the productive horizon in order to increase drainage. Well profiles may vary, but the top of the deviated wellbore must be vertical, followed by a deviation of the calculated azimuth. Therefore, the main task of the telemetry system in directional drilling is to constantly monitor the planned trajectory, as well as to maintain the bit trajectory within the corridor that runs inside the open formation.
\end{abstract}

\section{Keywords}

directional drilling, well profiles, telemetry system, navigation systems, inclinometers 


\section{Introduction}

The constant growth in the rates of exploration and production of oil and gas, an increase in the intensity of development of already found fields due to horizontal and pad drilling required a significant increase in the accuracy of diagnostics and active control of the spatial position of the wellbore.

The inclinometer is used as a measuring system in the most important technological process - well construction. According to its recordings, the surveyor monitors the compliance of the profile and well plan with the design task and adjusts the drilling process. Therefore, the accuracy of the measurements and the promptness of their presentation determine the cost of well construction in many respects.

A number of specialized Russian and international companies are developing such systems (Schlumberger, Sperry Sun-Halliburton, SIBNA-Tyumen, GyroLogic, etc.). However, Russian inclinometers are inferior to international ones in technical characteristics, while the latter are very expensive.

Drilling wells of a complex profile is impossible without application of the up-to-date telemetry and navigation systems. Firstly, wells with complex trajectory with long horizontal sections in the limits of the productive horizon and multilateral wells cannot be drilled without operation control of the bottom-hole position. Modern telemetry systems are used for monitoring the position of the bottom of the well being drilled. In addition, they are used to obtain various information from the bottom of the well, for example, the parameters of the drilling mode - values of axial load, torque and bit speed.

Directional drilling is a method of well construction with a deviation from the vertical in a designed direction. Directional drilling is used both for drilling oil and gas wells and for the exploration of solid mineral resources. The most efficient field of application of directional drilling is developing fields in water areas, in swampy or highly rugged areas and places, where the construction of drilling rigs may violate environmental protection conditions. Directional drilling is also used to create relief wells for killing blowouts (Vasko et al., 2020; Blatnicky et al., 2020) for multilateral wells or deviation of the lower part of the well along the productive horizon in order to increase drainage.

Directional drilling of oil and gas wells is carried out according to special profiles. Well profiles may vary, but the upper section of the deviated wellbore must be vertical, followed by a deviation in the projected azimuth (Aliev et al., 2013; Baranov et al., 2017; Blatnický et al., 2020; Bozek 2013; Grudz et al., 2020; Ivanova et al., 2018)

\section{Material and Methods}

Selection of the telemetry system depends on the type of formation, the thickness of a layer, curvature, bit diameter, designed tasks. The major task of the telemetry system during directional drilling is constant control over planned trajectory as well as keeping the bit inside the "corridor", which goes in the boundaries of the opened layer

- During directional drilling, telemetry systems should provide:

- Fast data exchange.

- Visual clarity of the data.

- Accuracy of the transmitted data.

- Safety of the data in case of failure of communication channel.

- Real-time data receiving.

- Close location of the recording point to the bottom.

- Binding of the collected data to the depth.

- Binding of coordinates to geological conditions.

Telemetry tracking of directional drilling is the process of receiving all the needed information from each section, where drilling works are being fulfilled. All the collected data are transmitted to the special unit, where their assortment, processing and recording is fulfilled. Obtaining information enables the operator of telemetry equipment to analyze the data received and take the necessary measures that are related to the process of drilling and aimed at preventing an emergency. Telemetry tracking of directional drilling consists of three components. Nowadays, three main methods of data transmission during drilling are the most widespread. They include hydraulic, electric wire and electromagnetic communication channels. The hydraulic channel is the most reliable and efficient because the drilling mud column serves as a conductor, excluding extra costs on providing signal transmission. Current developments and materials give an opportunity to transmit information about drilling parameters without significant distortions. Telemetry systems allow directional drilling in any climate conditions regardless of the subsoil composition (Khanzhina et al., 2014; Kopas et al., 2017; Krenicky, 2011; Murcinkova and Krenicky, 2013). 


\section{Tasks of downhole measurements by telemetry systems}

Tasks of downhole measurements by systems, using communication channel "bottom - wellhead" can be divided into three main groups (Vakhitov, 2010; Senkevich et al., 2016):

1) operational technological control over the well drilling mode in order to optimize it;

2) control of the direction of drilling in order to regulate the process of directional drilling along a given trajectory;

3) lithological layering of the geological section of the well, the study of the parameters of the formations not distorted by the penetration of the filtrate of the drilling fluid, identification of reservoir formations, prediction of zones of abnormal reservoir pressures.

Having data on the bit speed and true axial load on the bit, it is possible to maintain the drilling mode in such a way that the maximum ROP is provided, wearing of the bit is controlled, and critical modes of its operation are avoided.

Due to constantly increasing volumes of pad drilling, directional and horizontal drilling (including protection of the environment), the problem of control over wellbore direction during its drilling becomes relevant as well as the solution how to manage this process according to the planned program. The complex of sensors for wellbore direction control should consist of sensors measuring buildup angle and azimuth of a well. To control the process of the directional drilling measurement system is also equipped with a deflector position sensor. Two described groups of sensors can be unified into one telemetry system for optimization of the directional and horizontal drilling process.

In some cases, it is rational to have the additional information from the well bottom. For example, to determine whether there are leaks in tool joints or not, the data about drilling mud flow rate can be useful, while for studying thermal conditions of drilling, it is reasonable to measure bottom-hole temperature (Saga et al., 2020).

The vibration of the drilling tool is a very informative parameter for drilling, too. It characterizes both the process of destruction of rocks and the properties of the formations being drilled (elastic characteristics, lithological composition, etc.).

Measurement of geophysical parameters during drilling allows collecting data about the lithological composition and specific electrical resistances of strata, which were not exposed to penetration of filtrate of drilling mud. It provides reliable separation of productive horizons, while the change in characteristics of formations allows the prediction of zones of abnormal reservoir pressure and productive layer boundaries. What is more, the presence of geophysical probes of various depths in the measuring complex provides an opportunity to measure reservoir parameters with the purpose of studying the dynamics of the formation of the zone of penetration of drilling fluid filtrate in the bottom-hole zone.

Measurement of natural radioactivity of rocks surrounding the well gives the possibility to fulfil lithological layering of the section and, combined with electric characteristics of the formation, to determine formation boundaries and separate the section into interlayers. Usually, the geotechnical well testing station controls the drilling mode according to surface sensors readings. They include measurement of (rate of penetration) ROP, weight on hook (WOH), drilling mud flowrate, standpipe pressure (SPP). In addition, gas logging and fluorescence logging data are used.

Geophysical survey data obtained during drilling can serve as a reliable criterion for interpreting the results in most wells for the purpose of further planning of well operations (testing of objects, core sampling, etc.). In these cases, the geophysical survey complex carried out by the equipment on the cable can be shortened, and the time required for logging can be reduced.

Combining the above complexes into a single telemetry system requires the transmission of a large amount of information and can only be implemented with a high throughput channel.

A characteristic feature of telemetry systems is that failure of any block of downhole equipment leads to loss of information until the end of the trip and requires the removal of a downhole tool to the earth's surface to restore its work ability.

Increased vibrations, the influence of aggressive and abrasive environment, impact loads, extensive and compressive loads, torsion, high pressure and temperature require the development of special measures of protection, use of wear-resistant high-strength materials, durable coatings.

Taking into account specific requirements to well measurement systems of different purpose helps to provide needed reliability and extension of operational life in well conditions. Providing reliable operation during considerable vibrations and mechanical loads is of great importance.

Thus, the complex of downhole measurements during drilling determines the technological mode of drilling and includes the next parameters: bit speed, axial load and torque, bit vibrations, flow rate and temperature of drilling mud, angle parameters of trajectory.

Registration of natural radioactivity of rocks, measurement of acoustic and electrical properties of rocks surrounding the borehole during drilling provide lithological layering of the geological section, determination of 
the reservoir saturation, identification of zones of abnormal reservoir pressures, direction-finding of the boundaries of the productive reservoir in inclined flat and horizontal sections of oil and gas well drilling.

Comparative characteristics of wireless telemetry system BTS and wireless telemetry system with electromagnetic channel ABTS - EM are shown in Table 1.

Table 1. Comparative characteristics of wireless telemetry system BTS and ABTS-EM.

\begin{tabular}{|c|c|c|c|}
\hline \multicolumn{2}{|l|}{ Parameter } & $B T S-172$ & ABTS-EM-172 \\
\hline \multicolumn{2}{|l|}{ Type of drilling } & Turbodrilling (considered as rotary) & Rotary \\
\hline \multicolumn{2}{|l|}{ Presence of metric tapered thread } & $\begin{array}{l}M K 156 \times 5,5 \times 1: 32 \\
M K 150 \times 6 \times 1: 8\end{array}$ & No \\
\hline \multicolumn{2}{|l|}{ Tool joint thread } & $\begin{array}{l}Z-133 \\
Z-147 \\
\end{array}$ & $Z-147$ \\
\hline \multicolumn{2}{|l|}{ Probe length, $m^{*}$} & 4,26 & 3,5 \\
\hline \multicolumn{2}{|c|}{$\begin{array}{l}\text { Magnetometer to nearest magnetic BHA part } \\
\text { distance, } \mathrm{mm}\end{array}$} & 1800 & $\begin{array}{l}1800 * \\
4700^{*}\end{array}$ \\
\hline \multicolumn{2}{|c|}{ Maximum permissible weight on bit, $t$} & 20 & 40 \\
\hline \multirow{2}{*}{$\begin{array}{l}\text { Maximum Dogleg Severity } \\
\text { degrees per } 10 \mathrm{~m}\end{array}$} & Non-rotating & 1,6 & 3,0 \\
\hline & Rotating & 2,5 & 3,5 \\
\hline \multirow{2}{*}{$\begin{array}{l}\text { Maximum permissible rotation, } \\
\text { rpm }\end{array}$} & Straight angle & 60 & 100 \\
\hline & $\begin{array}{l}\text { Drift angle } \\
\text { buildup }\end{array}$ & 30 & 80 \\
\hline \multicolumn{2}{|l|}{ Maximum torque, $k N^{*} m$} & 20 & 36 \\
\hline \multicolumn{2}{|l|}{ Permissible mud acidity, $p H$} & $7<p H<10$ & $5<p H<11$ \\
\hline \multicolumn{2}{|l|}{ Emitting rated current, $A$} & $15-17$ & $30(50) * *$ \\
\hline \multicolumn{2}{|l|}{ Emission power, $W$} & 100 & $200(500)^{* *}$ \\
\hline \multicolumn{2}{|l|}{ Drilling mud flow rate, $l / s e c$} & $28-54(64) * *$ & $26-55(64) * *$ \\
\hline
\end{tabular}

1. $\quad *$ - depends on collar variation

2. $\quad * *$ - severe conditions

Acoustic communication channel

\section{Communication channels}

The systems with acoustic communication channel use sound oscillations, which are distributed along the well through drilling mud, drill string or rock. Therefore they are divided into three types: hydroacoustic, acousticmechanical and seismic.

Among the three types of downhole telemetry systems (DTS) with an acoustic communication channel, the seismic systems are used only for passive control of the bottom hole coordinates. Due to the lack of accuracy in determining the position of the well bottom (tens of meters), they are still at the stage of scientific and experimental research.

The hydroacoustic channel is poorly studied because of its complexity and variety of properties in the borehole. Until recently, DTS with a hydroacoustic communication channel has not been used in practice. One of the central problems in creating a hydroacoustic channel (HAC) is the development of a low-frequency (up to 100 ... $200 \mathrm{~Hz}$ ) emitter capable of the efficient creation of vibrations inside the drill pipe string in the well.

DTS-HAC system was meant for finding the orientation parameters of the horizontal or directional borehole as well as service parameters, reflecting operation conditions during drilling.

The equipment for information transmission (EIT) through the hydroacoustic communication channel allowed receiving acoustic signals without pumping of the mud from a depth of $1000 \mathrm{~m}$, with pumping - from a depth of $200 \mathrm{~m}$. In addition to the drilling mud, the drill string itself could be the channel for information transmission (Qazizada et al., 2017; Qazizada et al., 2017; Vasylyshyn et al., 2020). In general, the results of 
testing of the EIT equipment showed that the hydroacoustic channel can be used as a highly reliable and inexpensive means of communication, in particular, in the DTS with a combined channel.

Schlumberger has now proposed the transmission of acoustic signals while drilling wells. A characteristic feature of the proposed telesystem is its independence from the parameters of the drilling mud since the acoustic signal propagates through the pipes and only on the surface is it transformed into electromagnetic oscillations. The device includes a hollow rod with the sensors on its surface, which is placed in a drill pipe and connected to it by means of mechanical and electrical contacts.

\section{Telemetry systems with the hydraulic communication channel}

The hydraulic communication channel has found wide use due to the following advantages:

- hydraulic communication channel is a natural channel because drilling mud column is used for the transmission of information. Consequently, additional expenses on the creation of communication channel are avoided;

- hydraulic communication channel has a large range of operation.

The first telemetry systems consisted of mechanical devices, where a drive unit was connected with a hydro turbine motor shaft. These included hydraulic turbine tachometers (GTN-2, GTN-3, GTN-4, GTN-PN, ICHT), which were the only instruments providing continuous control of the operating mode of the turbine downhole motor. Hydraulic turbine tachometers have been successfully used for drilling test wells, producers and superdeep wells (The Kola Superdeep Borehole SG-3 and Saatlin Superdeep Borehole SG-1).

A more perfect telemetry system with a hydraulic communication channel for directional drilling allowed controlling azimuth, zenith angle and direction of deflector action. This system was named "drilling direction signaler" (SNB) and then renamed as "hydraulic inclinometer system" (GIT).

The most successful companies in the field of logging-while-drilling (LWD) include Schlumberger, Halliburton (USA), Sperry-Sun (Great Britain), Baker Hughes, Teleco, Eastman Cristensen (USA). At the end of the 1980s, these companies developed and now use measurement-while-drilling (MWD) systems with a hydraulic communication channel, which allow real-time control of the trajectory of wells by measuring inclinometric parameters, several technological parameters and, in some cases, GL and SG.

Currently, international companies are developing and proposing LWD systems with hydraulic communication channel with a set of methods, which are not inferior to cable logging systems. Usually, these systems consist of separate units, each of them has a memory storage device, providing a recording of well data during operation. What is more, the information about layers is transmitted to the surface in real-time mode. Socalled "negative" and "positive" impulse systems have been developed and found wide use. During the "positive" impulses (Fig. 1), the in-pipe space is closed by the valve, which leads to an increase in the in-pipe pressure. This surge (by $0.7 \mathrm{sec}$ ) of pressure is the pulse of the main signal, which is recorded by the pressure sensor, installed into the manifold, and then by the surface equipment, included in the telemetry kit. In the case of "negative" impulses (Fig. 1), the valve opens and releases the drilling mud into the annulus, and at the same time, there is a pressure drop (by $0.7 \mathrm{sec}$ ). The impulse is recorded the same way.

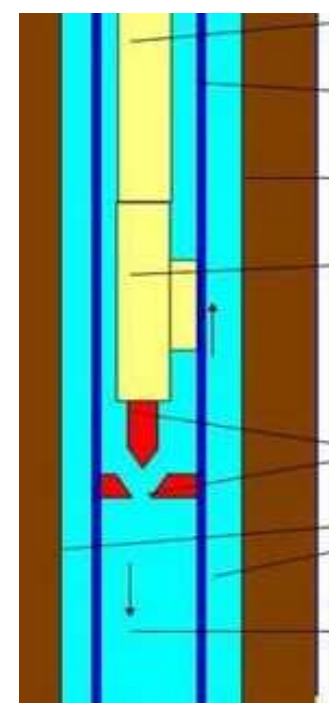

inner part of the device

outer part of the device

borehole wall

electromagnet

shutoff valve

annular space

in-pipe space

Fig. 1. Device for transmission of signal with "positive" impulse

Another relevant and perspective direction is the development of geosteering systems, allowing selection and correction of well path on the base of geological data about the formation, received in real-time mode. In 
comparison with older generation systems, where measuring sensors were placed 9-30 meters above the bit, new telesystems sensors are located near the bit.

An example of such telesystems is the new MWD device of Halliburton Strata Tracher (TM). It is the first industrial small-size device, measuring gamma-ray radiation along with scanning of azimuth, deflection on the bit, dynamic and static deviation survey and the change in bit speed. Sensor recordings are processed and then transmitted through a "short line" on the separate unit located above the motor of BHA. Transmission is made through an electromagnetic channel. The upper unit is connected with a high-speed inclinometer PathFinder ${ }^{\mathrm{TM}}$ for transmission of the data through a hydraulic communication channel to the surface in real-time mode.

Baker Hughes INTEQ also has more than fifteen years of experience in conducting MWD in any drilling conditions in fields around the globe. The company has a complete series of MWD systems for both direction control and formation assessment, designed for temperatures of $125 \ldots 150{ }^{\circ} \mathrm{C}$ and pressure of $140 \mathrm{MPa}$. These include: MWD navigation devices of small diameter - Teleco Navigamma and Teleco Navitrac, MWD navigation devices of large diameter - Navigator, Teleco DDG and DG, devices for logging-while-drilling Teleco MDL, MNP and DPR, forming combined tool Triple Combo. The company has also developed a tool, combining the Navitrac navigation system, which measures resistance - NaviMPR and Teleco RGDä device to measure specific resistance and inclinometry parameters and GL (Fig. 2).

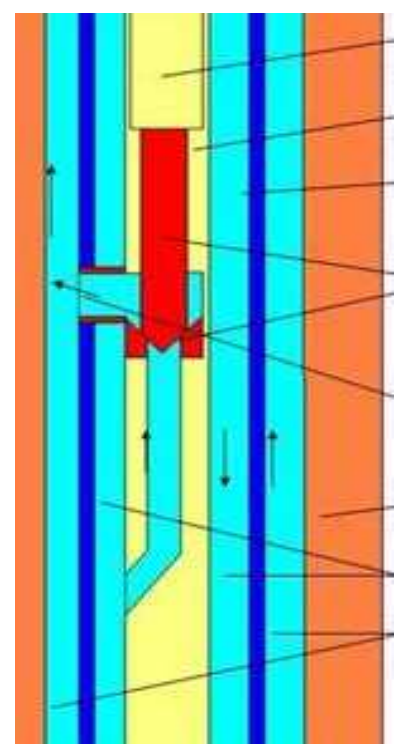

electromagnet

inner part of the device

outer part of the device

bypass valve

discharge hole

borehole wall

annular space

in-pipe space

Fig. 2. Device for transmission of signal with "positive" impulse

Schlumberger is promoting a new device Slim Access, which can be lowered on pipes into a redrilled well with a diameter of $95 \mathrm{~mm}$ and fast buildup - 40 degrees per $30 \mathrm{~m}$. The use of this device helped Albert Energy Co. to decrease the daily logging time for a complex section of the well below the drill string with open ends (Kuric et al., 2019; Liaposhchenko et al., 2019; Pchela et al., 2019).

One of the examples of technical solutions aimed at the improvement of hydraulic communication channel is another development of Schlumberger - interference-free generator of intensive pressure impulses for MWD system. The system provides the maximum intensity of signals under the minimum probability of distortion of the signal, which can be caused by suspension particles in the drilling mud. This system consists of a stator with holes through which the drilling mud penetrates and a rotor, rotating relatively to the stator. As a result, pressure impulses are formed.

\section{Electromagnetic (wireless) communication channel}

In the case of a wireless electromagnetic communication channel, the drill string is used as one of the transmission line conductors. Due to the simple construction of downhole and surface equipment as well as high throughput, this channel is the most promising for establishing the reliable connection between the head and the bottom of the well during turbine and rotary drilling (Fig. 3).

In comparison with the hydraulic communication channel, the electromagnetic channel has the next advantages:

- increased reliability of parts of downhole equipment, which are in contact with an abrasive flow of drilling mud;

- simple regulation and feedback.

The range of operation of the electromagnetic channel highly depends on the specific electric resistance of the surrounding rocks. In low-resistivity rocks (Western Siberia) signal is strongly shunted and attenuated, while 
in the high-resistivity ones (thick salt layers in Orenburg, Perm) transmitter dipole of the telesystem becomes electrically insulated by the layers, and the signal transmission is bad. However, electromagnetic channels have considerable advantages, they are much cheaper, and the required quality of drilling mud is lower. In addition, the electromagnetic channel can be used in conditions where the hydraulic channel does not work.

However, the electromagnetic channel has several disadvantages, like dependence on pipe material and properties of the geological section, which can limit the range of operation of the channel. Another negative side is that it cannot be used in the sea and saliferous formations. Complex electronic operation unit also complicates the use of electromagnetic channel (Olkhovskaya, 2011; Novokshonov et al., 2017; Lipanova et al., 2020).

On the basis of technical solutions of the BETA-1 facility, the KUB-1 facility was developed, which is used for electric logging during turbine drilling. In the next decade, VNIIGIS developed telemetry system ZIS-1 for automated control over well direction during drilling and system "Zaboy" for measurement of geophysical and technological parameters during drilling of oil and gas wells.

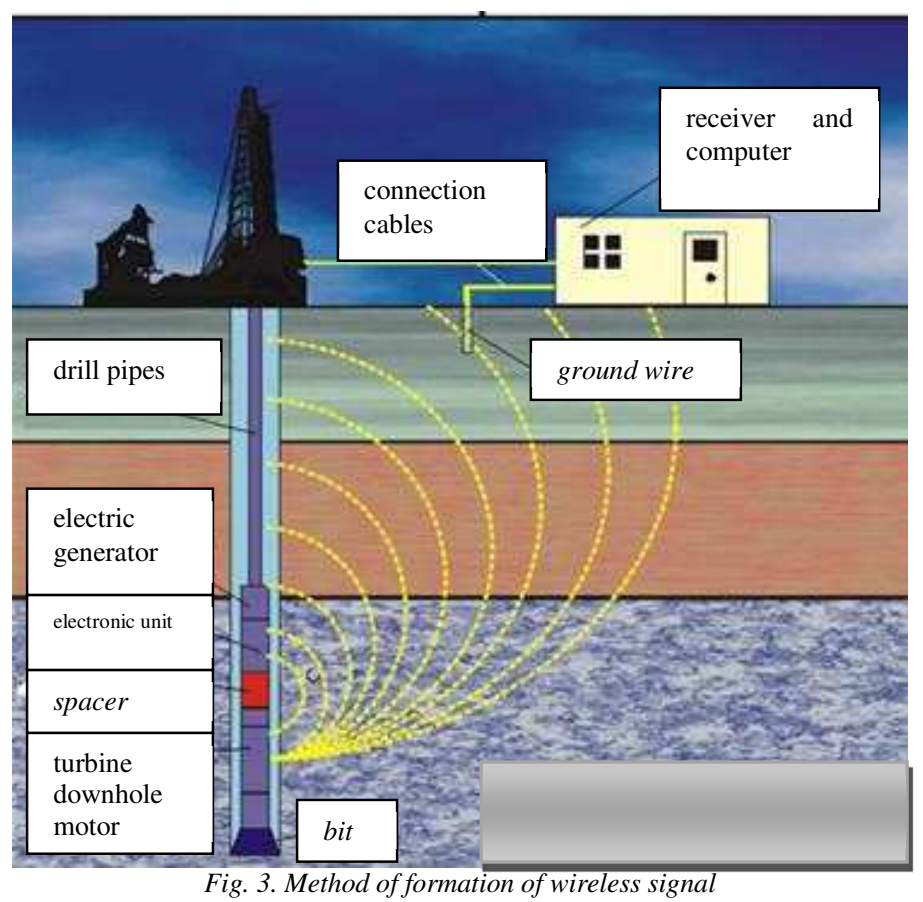

Downhole telemetry systems with wireless electromagnetic communication channel like ZIS-4 are used for horizontal drilling.

New small-size telesystems with wireless electromagnetic communication channel ZTS54-EM are used during the drilling of horizontal and directional sidetracks in the Tuymazinskoe drilling department of Bashneft. Since that time, more than 130 sidetracks have been drilled, including 10 horizontal ones, the maximum length of which is $250 \mathrm{~m}$.

Today, a more advanced telemetry system ZTS-42EM has been developed with a module diameter of $42 \mathrm{~mm}$. This telemetry system can be equipped with an additional module and a module above the bit.

\section{Wire communication channel}

The wire communication channel has the next advantages in comparison with other communication channels:

- maximum possible information content: fast operation, multichannel, resistance to distortions, reliable connection;

- absence of a downhole source of electric energy and power transmitter;

- possibility of two-way communication;

- possibility to supply considerable electric power for drives of downhole mechanisms (controlled deflector, loader and etc.);

- possibility to use during air flushing and during drilling with aerated drilling fluid;

- independence from specific resistance of rocks.

The telemetry system of STE type, where the power cable of the electric drill is used as a communication line, was the most widely used. It allowed measurements of zenith angle, azimuth, deflector position, load on a bit, bit speed, torque. Most telemetry systems of this type had an operational life of $600 \ldots 800$ hours and overhaul period up to 100 hours, 
Currently, a range of unified telemetry systems of ETO (electric wire telesystem for navigation) type has been developed. Construction of ETO system provides increasing of measured parameters by addition of extra assembly units to the basic unit. The basic unit ETO-1 transmits the data about the deflector direction through a single-core logging cable. ETO-2 and its modifications control the zenith angle and position of the deflector through both three-core and single-core logging cables. ETO-3 controls three main parameters (zenith angle, azimuth, position of deflector) through a single-core logging cable. As for ETO-4, besides spatial parameters of the drilling path, it includes a gamma logging unit.

ETO-4T telesystem, which is being developed, consists of a downhole unit, lowered on electric cable, surface facilities for recording and displaying downhole data and technological equipment for registration of reservoir pressure and laying of cable communication line.

As for survey in vertical wells, the next equipment is used: inclinometry downhole system with cable communication channel KTS-1 with magnetometric multipoint inclinometer "Onyx"; technologies and technical means for well logging in horizontal wells "Horizontal - 1" using a geophysical cable, "Horizontal - 2" using an electric drill cable, "Horizontal - 3" and "Horizontal - 4" on a cable with delivery to the bottom-hole by a flow of drilling mud or a string of special pipes.

To solve one of the urgent problems of sidetracking, a computerized information and navigation system (CINS) was developed. It includes an ORBI-36 orienting device, which allows measuring the position of the deflector relative to the apsidal plane of the well during drilling using a geophysical cable as a communication channel.

To control well trajectory, CINS should include computerized inclinometer IMMN36-100/40, used for measurements of azimuth, zenith angle and position of deflector relative to magnetic meridian and apsidal plane. Inclinometer measurements should be conducted during stops of the drilling process. In addition, the inclinometer measures the depth by the cable and corrects it using magnetic stickers. The inclinometer consists of downhole and surface devices and a personal computer of IBM type (Laptop).

Development of a small-size three-parameter inclinometric telesystem, measuring an azimuth, zenith angle and angle of deflector position gave an opportunity to carry out measurements at a speed of $1500 \mathrm{mph}$. This system is equipped with an up-to-date computer recording system located on the surface. The control of depth is fulfilled using a logging cable by means of a selsyn transmitter.

Cable DTS (Of STT, KTS-1 type) are mainly used in southern oil-producing regions, and they are not widely used.

The method of horizontal drilling, including special deflectors, an inclinometric system of the CTT type with a cable communication channel and a set of technical devices, is based on the use of centralizers and eccentric stabilizers with elastic support bars in the BHA. This provides drilling horizontal wells along calculated trajectories in different geological conditions. The horizontal drilling complex also includes an articulated sleeve that connects the assembly guide rod or deflector to the drill string. This method does not require constant rotation of the drill string for drilling straight sections of the wellbore. It significantly simplifies the method of drilling horizontal wells, compared to Western methods, and allows using Russian drilling tools without reliability reduction.

\section{Combined communication channel}

The combined communication channel is a combination of channels of different nature, connecting the downhole device with recording and processing equipment located on the surface. The structure scheme of the combined communication channel is shown in Figure 4.

In spite of additional expenses, the use of combined channel helps to avoid the disadvantages of wire channels, which are difficult to install but have high throughput, and disadvantages of electromagnetic channels, which are easy in operation but have limited operation range in low-resistivity rocks.

It should be mentioned that the selection of the type of communication channel depends on the geological and technical conditions of drilling.

For example, the requirement for the reliability of the hydraulic channel dictates the need for thorough cleaning of the drilling mud from abrasive material (no more than 1-2\% of sand), which causes certain difficulties in cleaning the drilling fluid when drilling a well in harsh climatic conditions. At the same time, the use of a hydraulic channel is limited in the presence of gas (air, etc.) in the drilling fluid, which excludes its use when drilling wells with aerated solutions.

The combination of a hydraulic and electromagnetic channel, hydroacoustic and wire, electromagnetic and wire can be implemented in various telemetry systems and expand the area of geological and technical problems solved by telemetry systems during drilling and operating horizontal wells. 


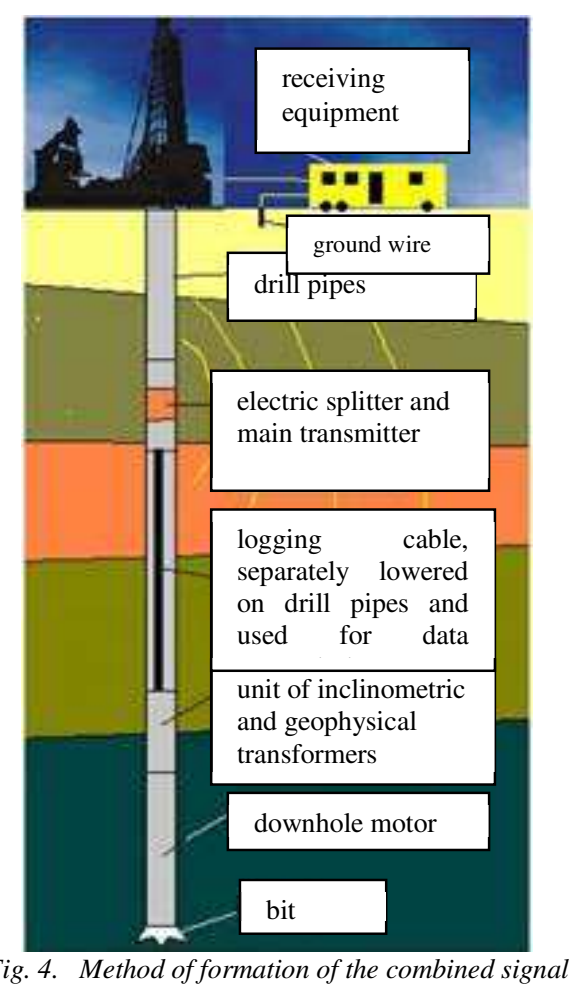

Methods for calculating a combined communication channel use the previously described techniques and programs for certain types of communication channels, and, in each specific case, the optimal version of the system can be selected (Table 2).

Table 2.Variants of the combination of channels connecting with the bottom

\begin{tabular}{|c|c|c|}
\hline Combination purpose & $\begin{array}{c}\text { Combination of } \\
\text { channels }\end{array}$ & Combination result \\
\hline $\begin{array}{c}\text { Increase in operation range and } \\
\text { throughput of the channel }\end{array}$ & $\begin{array}{c}\text { Cable }+ \\
\text { electromagnetic channel }\end{array}$ & $\begin{array}{c}\text { Range of operation and throughput } \\
\text { increase, the system becomes more } \\
\text { complex }\end{array}$ \\
\hline $\begin{array}{c}\text { Increase in throughput of the } \\
\text { channel }\end{array}$ & $\begin{array}{c}\text { Cable }+ \text { acoustic } \\
\text { channel }\end{array}$ & $\begin{array}{c}\text { The system becomes more complex and } \\
\text { can work when drilling is stopped }\end{array}$ \\
\hline $\begin{array}{c}\text { Increase in throughput of the } \\
\text { channel }\end{array}$ & $\begin{array}{c}\text { Cable }+ \text { hydroacoustic } \\
\text { channel }\end{array}$ & $\begin{array}{c}\text { Range of operation and throughput } \\
\text { increase }\end{array}$ \\
\hline $\begin{array}{c}\text { Increase in operation range of } \\
\text { electromagnetic channel }\end{array}$ & Use of retransmitters & $\begin{array}{c}\text { Range of operation and throughput of } \\
\text { electromagnetic channel increase, the } \\
\text { system becomes more complex }\end{array}$ \\
\hline
\end{tabular}

Long horizontal and extended reach wells are the most popular type of directional drilling today. The complexity of drilling of such wells is compensated by the increased efficiency of hydrocarbons extraction due to the extended contact area with the productive formation.

The construction of such wells is connected with a range of technological and technical problems, the solving of which is one of the priority directions of drilling development. Since the 1950s, most directional wells are drilled with the use of steerable downhole motors (hereafter referred to as screw downhole motor (SDM)). The reasons to use this technology are simple and reliable construction, relatively low cost of operation and maintenance, a wide range of configurations for specific parameters and directional drilling tasks. However, along with the obvious advantages of using steerable downhole motors, there are considerable drawbacks due to the construction features and operation modes of SDM. The most meaningful of them:

- Drilling with the use of a downhole motor does not allow achieving a uniform borehole curvature: the trajectory consists of alternating sections of conventionally straight sections of rotary drilling with rotation of all elements of the drill string and sections of directional drilling in the sliding mode of the BHA with the creation of areas of high local curvature intensity. This causes an increase in torque during rotation of the assembly, excessive wear of tool joints of drill pipes, problems during hole $(\mathrm{RIH} / \mathrm{POOH})$ operations and lowering of casing 
- In rotary drilling with the use of SDM, bending of the deflecting section forces the bit to rotate with deviation from its axis, which causes a larger borehole diameter and the development of a spiral groove. The wellbore walls are rougher, which increases twisting and axial loads on the drill string. This can also cause a problem when running completion equipment.

- In the process of bottom-hole deepening, when zenith angle and distance from wellhead grow, the problem of uniform loading of BHA units (bit - SDM) occurs, and consequently, directional drilling efficiency falls. The worst impact is exerted during drilling of horizontal sections, often being the main cause of incompliance with planned well trajectory, violation of productive zone boundaries and non-reaching the calculated bottom-hole of the section.

- Technological feature of the volumetric screw downhole motor is an increase in differential pressure drop with the growth of load on the bit during the drilling process. Practical experience shows that in most cases, the maximum pressure drop is reached at an incomplete allowable load on the bit. Moreover, incompliance of the conditions for smooth touching the bottom and the subsequent uniform increase in the weight on the bit during drilling cause an abrupt increase in the differential drop, which in turn reduces the service life of the PDM, components of telemetry systems, as well as surface equipment and mud pumps.

- The increasing skew angle of deflecting section of SDM puts a limit on the rotation speed of a drill string, which, in turn, influences the quality of cleaning of the well during drilling and borehole reaming. Reverse reaming from bottom to head is operation out of specification, and it may damage the deflecting section and destroy the bearing block of the SDM spindle.

- Low ROP during the sliding mode of drilling increases the probability of sticking of BHA elements.

- Spontaneous deflection of a wellbore under the action of geologic conditions and drilling parameters. These and other factors can lead to troubles during drilling and completion of wells, which considerably increase time losses and, consequently, financial expenses of oil and gas producing companies. The development of automated systems of steerable rotary drilling has solved these problems. The use of rotary steerable systems provides continuous control over well trajectory with a constant rotation of elements of bottomhole assembly (BHA), which significantly simplifies drilling of wells with complex trajectory, including the wells with long horizontal section. All these allow drilling of wells with a high DDI index (Drilling Difficulty Index).

The efficiency of rotary steerable systems (RSS) is determined by the next circumstances:

- Achieving a smooth and uniform wellbore profile in all sections of the drilled interval due to the absence of directional drilling intervals (Fig. 5);

- Time required for drilling a section decreases due to the absence of such technological operations like waiting for a signal from the downhole telemetry system to identify the direction of deflector and orientation of SDM.

- Increase in rate of penetration (ROP) in a mode of $100 \%$ of rotary drilling in comparison with the sliding mode of drilling with use of SDM (Fig.6)

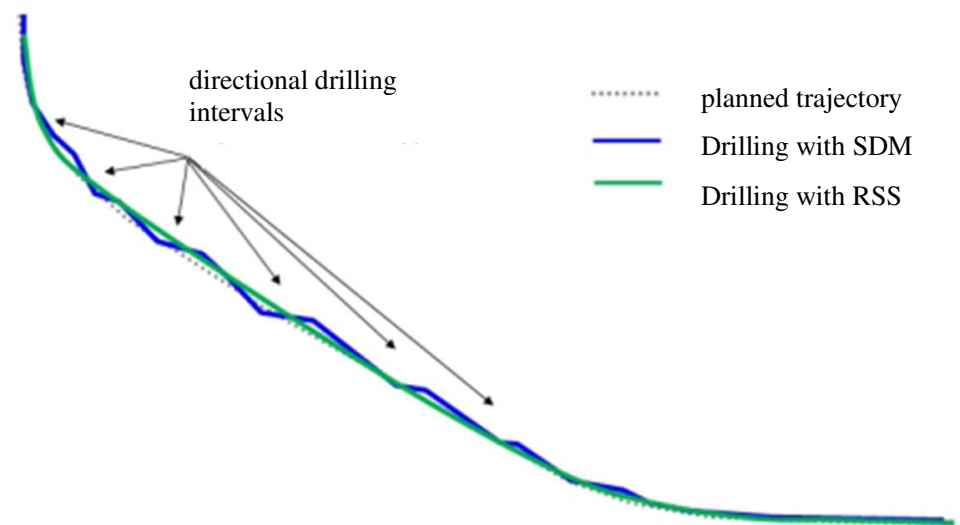

Fig. 5. Comparison of planned and actual trajectory of a wellbore 


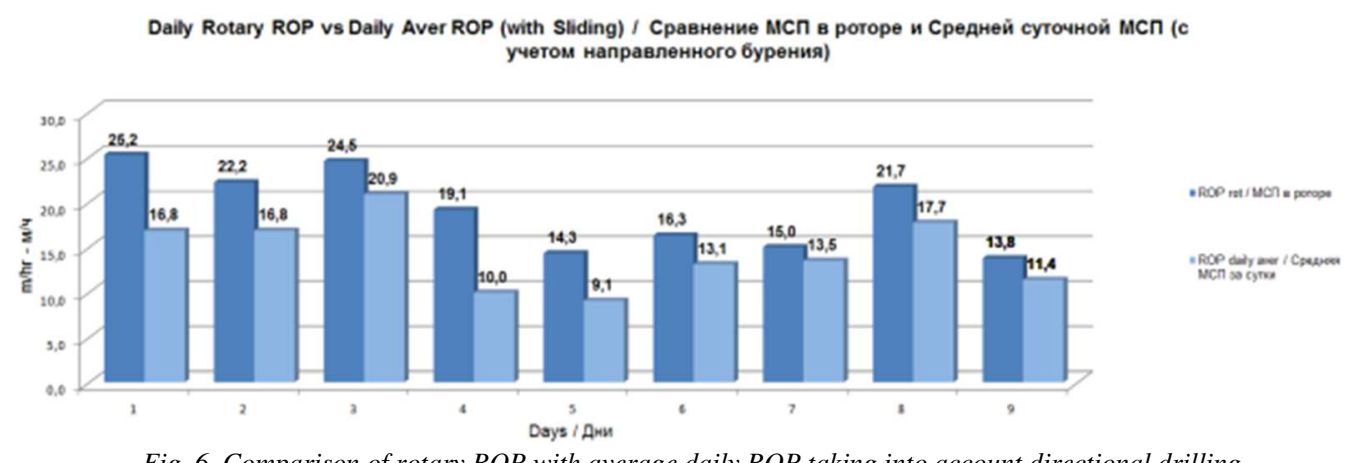

Fig. 6. Comparison of rotary ROP with average daily ROP taking into account directional drilling

- Increase in ROP and length of horizontal section due to reducing the friction force between the string and borehole walls because of rotation of the whole string. Uniform loading of the bit and absence of differential pressure drop;

- Improvement of bottom-hole cleaning due to drilling with a constant rotation of a drill string.

\section{Use of DTS on Karsovayskoye field}

\section{Conclusion}

A downhole telemetry system with an electromagnetic/hydraulic communication channel is used for drilling and operation control over drilling of sidetracks, directional and horizontal wells. The use of DTS allows measurement of navigation and geophysical parameters during drilling and "in static mode" without circulation of drilling mud. It also allows the recording of information during POOH operation. The use of DTS during well construction provides drilling without accidents, achieving a more accurate profile of directional wells and maximum compliance with design parameters. In the case of including DTS with hydraulic communication channel into BHA, we observed the decrease in time required to fulfil different operations during well construction. Thus, the time for RIH/POOH operations, the connection of drill pipes, gauging and flushing decreases almost by half. The time for fulfilment of geophysical works gets reduced by 1,6 - 3 times, while the time required for assembling and replacement of BHA decreases by more than 1,5 times.

\section{References}

Aliev, Sh.N., Huseynov, O.Kh., and Rustamov, E.M. (2013). Sucker rod pumps with double-action / Oil industry. №11. P.30-32.

Baranov, M.N., Bozek, P., Prajova, V., Ivanova, T.N., Novokshonov, D.N. and Korshunov, A.I. (2017). Constructing and calculating of multistage sucker rod string according to reduced stress. In Acta Montanistica Slovaca. Vol. 22, no. 2, 107-115.

Blatnicky M., Saga M., Dizo J., Bruna M.: Application of Light Metal Alloy EN AW 6063 to Vehicle Frame Construction with an Innovated Steering Mechanism, Materials, Vol.13, Issue 4, Article No: 817, DOI: 10.3390/ma13040817, 2020

Bozek, P. (2013). Robot path optimization for spot welding applications in automotive industry. In Tehnicki Vjesnik - Technical Gazette. Vol. 20, No. 5, 913-917.

Grudz, V., Grudz, Y., Zapukhliak, V., Chudyk, I., Oberezhny, L., Slobodyan, N. and Bodnar, V. (2020). Optimal gas transport management taking Into account reliability factor. Management Systems in Production Engineering. Vol. 28, issue 3. 202-208.

Ivanova, T.N., Korshunov, A.I. and Koretckiy, V.P. (2018). Dual Completion Petroleum Production Engineering for Several Oil Formations Management Systems in Production Engineering. Volume/Issue: Volume 26: Issue 4. 217-221.

Qazizada, M. E., Pivarciova, E. and Bialy, W. (2017). Centrifugal pump characteristics computation and reliability evaluation at variable speed driven. ICCT: 5th International Conference on Chemical Technology, Mikulov.

Qazizada, M. E., Pivarciova, E. and Bialy, W. (2017). Comparison of Gear and Peripheral pumps performance, evaluation of their reliability at operation region International Journal of Safety Science Vol. 01, No. 02, pp. 29-39.

Khanzhina, V., Kovalev, A. and Zinoviev A. (2014). Justification of Well Type and Design Depending on Depletion Mechanism of High-Viscosity Oil Production. Applied Mechanics and Materials, vol. 698, Trans Tech Publications, Ltd., Dec. pp. 674-678., doi:10.4028/www.scientific.net/amm.698. 674.

Kopas, P., Saga, M., Baniari, V., Vasko, M. and Handrik, M. (2017). A plastic strain and stress analysis of bending and torsion fatigue specimens in the low-cycle fatigue region using the finite element methods. XXI Polish- 
Slovak Scientific Conference Machine Modeling And Simulations MMS 2016, Procedia Engineering, Volume: 177, 526-531.

Krenicky, T. (2011). Implementation of Virtual Instrumentation for Machinery Monitoring. In: Scientific Papers: Operation and Diagnostics of Machines and Production Systems Operational States: Vol. 4, RAM-Verlag, Lüdenscheid, 5-8.

Kuric, I., Cisar, M., Tlach, V., Zajacko, I., Gal, T. and Wiecek, D. (2019). Technical Diagnostics at the Department of Automation and Production Systems. In Intelligent Systems in Production Engineering and Maintenance, Advances in Intelligent Systems and Computing, Volume: 835, 474-484.

Liaposhchenko, O. Pavlenko, I. Ivanov, V. Demianenko, M. Starynskyi, O.Kuric, I. And Khukhryanskiy, O. (2019). Improvement of Parameters for the Multi-Functional Oil-Gas Separator of "HEATER-TREATER" Type. 2019 IEEE 6TH INTERNATIONAL CONFERENCE ON INDUSTRIAL ENGINEERING AND APPLICATIONS (ICIEA), 6th IEEE International Conference on Industrial Engineering and applications (ICIEA), Pages: 66-71.

Lipanov, A., Lechev, A., Ovcharenko, P., Delgado Sobrino, D., Kolesnikova, L. and Stherkov, K. (2020). Selection of optimal modes of obtaining broad fractions of light hydrocarbons from oil-associated gas at oil production sites. Acta Montanistica Slovaca, Volume 25, Number 1, 1-13.

Murcinkova, Z. and Krenicky, T. (2013). Applications utilizing the damping of composite microstructures for mechanisms of production machines and manipulator devices. In: SGEM 2013: 13th Int. Multidisciplinary Sci. Geoconf. Vol. 1: 16-22 June, Albena, Bulgaria. Sofia: STEF92 Technology, 23-30.

Novokshonov, D.N., Baranov M.N. and Ivanova, T.N. (2017). Reliability Improvement of Sucker-Rod String at Directional and Horizontal Wells // «Intelligent Systems in Manufacturing ». - Izhevsk: Publishers house: Kalashnikov Izhevsk State Technical University. Vol 15, № 1.110 - 113.

Olkhovskaya, V.A. (2011). Underground hydromechanics. Non-Newtonian oil filtration. - M.: JSC VNIIOENG. 221.

Pchela, K.V., Gornov, D.A., Kireev, I.I., Bagryantsev, M.S., Manasyan, A.E., Amirov, A.A., Kashaev, D.V. and Sereda, I.A. (2019). Optimization of technological solutions in the development of deposits of super-viscosity oil based on data from core studies and oil properties. Oil. Gas. Novatsii. No.7, pp. 79-85.

Saga M. Blatnicka M. Blatnicky M. Dizo J. and Gerlici J.: Research of the Fatigue Life of Welded Joints of High Strength Steel S960 QL Created Using Laser and Electron Beams, Materials, Vol.13, Issue 11, Article No: 2539, DOI: 10.3390/ma13112539, 2020

Senkevich, I., Grigorov, B.A. and Mardupenko, A.A. (2016) Technological Processing of Oil Waste. Oil Gas Res, 2:115.

Vakhitov, T.M. (2010). Integrated solutions to improve the reliability of downhole equipment operation in difficult conditions at the fields of JSOC Bashneft. Magazine "Engineering Practice".№ 6.

Vasko M., Saga M., Majko J., Vasko A., Handrik M.: Impact Toughness of FRTP Composites Produced by 3D Printing, Materials, Vol.13, Issue 24, Article No: 5654, DOI: 10.3390/ma13245654, 2020

Vasylyshyn V., Taras, I., Bekish, I., Kornuta, O. and Kornuta, V. (2020). Partial cases of stressed-deformed condition of casing and pump compressor pipes. Management Systems in Production Engineering. Vol. 28, issue 2. 97-103. 